$\mathrm{V} \Delta \mathrm{K} 316.334 .3$

ББК 66.3(0), 4

DOI 10.22394/1682-2358-2020-4-95-102

O.V. Leonova, Candidate of Sciences (Economics), Docent of the Economics and Economic Security Department, Central Russian Institute of Management, Branch of the Russian Presidential Academy of National Economy and Public Administration

\section{FORMATION \\ OF A CONCEPTUAL FRAMEWORK FOR SUPPORTING YOUTH DEVELOPMENT IN THE CONTEXT OF STATE SOCIAL POLICY IN MODERN RUSSIA}

Topical problems of conceptual and normative foundations of state support for Russian youth in the framework of state social policy are analyzed. Key directions for modernizing the normative base of youth policy are considered. A study of draft laws in the field of state policy on youth support is conducted.

Key words and word-combinations: youth, youth policy, state social policy, youth affairs body.
О.В. Меоноља, кандидат экономических наук, дочент кафедри экономики и экономической безопасности Среднерусского института управления - филиала Российской академии народного хозяйства и государственной служби при Президенте РФ (email: oks980@rambler.ru)

\section{ФОРМИРОВАНИЕ КОНЦЕПТУААЬНОЙ ОСНОВЫ ПОААЕРЖККИ РАЗВИТИЯ МОАОАЕЖИ B KOHTEKCTE ГОСУААРСТВЕННОЙ СОЩИААЬНОЙ ПОАИТИКИ В СОВРЕМЕННОЙ РОССИИ}

Аннотация. Анализируются актуальные проблемы концептуального и нормативного обеспечения государственной поддержки российской молодежи в рамках государственной социальной политики. Рассматриваются ключевые направления модернизации нормативной базы молодежной политики. Проводится исследование законопроектов в сфере политики государства по поддержке молодежи.

Ключевые слова и словосочетания: молодежь, молодежная политика, государственная социальная политика, орган по делам молодежи.

K современном политическом знании развивается по нескольким направцениям.

Во-первых, методологические принципы политики государства в отношении моло- 
дых поколений рассматриваются с опорой на программно-целевой подхоА, через призму политико-управленческого проџесса. Например, в ряде научных трудов делаются попытки объединить системный подхоА с программно-цемевым управлением. Исходя из этого, эпиџентром усилий государства признается модернизаџия доктринальной основы и стратегических приоритетов молодежной политики. Ее содержание охватывает формат действий соџиально-экономического и организационного характера, цель которых - социально-правовая защищенность молодых граждан [1] .

КАассик современной отечественной гуманитарной мысли В.А. Ауков подчеркивал диалектический характер политики государства по поддержке развития молодежи. В широком значении под таковой преАлагалось понимать обоюдный процесс соџиальной коммуникации межАу обществом, его институџиями и духовными ценностями и соџиальной агрегаџией молодежи. В более конкретном значении поА молодежжной политикой понимают сферу государственной деятельности и деятельности негосударственных институтов по социализации и соџиальному развитию молодежки [2] .

Сущность политики государства в отношении молодежи проецируется на поддержку самодеятельных инициатив данной соџиальной группы и возникающих на ее основе молодежных объединений. Таким образом, управление формированием и практическим воплощением молодежной политики рассматривается как проџесс субъектно-объектного порядка. К его субъективной составляющей относится деятельность как государственных и муниципальных органов, так и молодежных объединений, их ассоџиаџий, молодежных активистов.

Во-вторых, распространена трактовка молодежной политики как самостоятельного сектора соџиально-экономической активности государственных или муниципальных институтов [3]. В таком случае стратегия подАержки и развития молодежи выражается в формате отдельного спеџиализированного направления государственной компетенции. Ее реализуют органы пубцичной власти по делам молодежи через управленческие проекты и программы. При этом их магистральной целью называются предотврашение ущемленного поможения, Аюмпенизации различных групп и категорий молодежи [4] .

Стало популярным расширенное толкование феномена молодежной политики как государственной деятельности по обеспечению вкАючения молодежи в соџиальную действительность. Исходя из этого, политика государства по поддержке молодежи рассматривается как функциональная задача публичной власти, фундаментальной задачей которой остается создание условий для саморазвития и самореализаџии молодых граждан.

С нашей точки зрения, наиболее предпочтительным и обоснованным представцяется отождествление молодежной политики в качестве элемента соџиальной политики государства [5] . Весьма аргументирована точка зрения Е.Г. САуџкого, согласно которой подАержкка молодежки органично вписывается в соџиально-экономическую стратегию государства. Она являет собой систему нормативных актов и практических действий по формированию и подАержанию необходимого соџиального статуса, качества жизни 
и соответствия молодежи значению субъекта соџиально-политических отношений [6].

Отметим, что существует и критическое восприятие отнесения молодежной политики к одному из компонентов соџиального сектора государственно-управленческой деятельности. Наиболее последовательный антагонист рассматриваемого подхода И.М. Ильинский провозглашает молодежь в качестве высшей ценности социального развития. ОАнако продвигаемую им гуманистическую концепцию молодежной политики следует признать достаточно идеализированной в контексте реалий соџиально-политических и политикоэкономических процессов в современной России.

Весьма аргументированными представмяются научные разработки, согласно которым именно молодежь становится наиболее уязвимой соџиальной группой в условиях глобальных общественных трансформаций. Необходимо принять во внимание мнение А.А. Цыбакова, который утверждает, что организационные политическая борьба перманентно совершенствуется на основе использования все более эффективных технологий и приемов давления на социальные грУппы и отдельных индивидов [7]. Именно поэтому необходимо осуществцять системную стратегию в сфере решения экономических проблем молодежи через подАержку мегальных политических движений, созданных при ее участии. ОАнако система государственной молодежкной политики в постсоветской России долгое время оставалась ориентированной на решение конъюнктурных проблем, что актуализирует потребность в совершенствовании ее доктринального обеспечения за счет учета объективных потребностей разцичных групп и категорий молодежки.

В понятие «государственная молодежная политика» сегодня включены практически все направления деятельности государственных институтов по реализации интересов и запросов молодежи. Ими охватываются такие сферы, как соџиализация и воспитание молодежи, ее соџиальная защита, а также идеологические воззрения и экспертные оџенки о месте и роли молодежки в современной России.

Убедительна аргументация С.Н. Чируна, который указывает на изучение политики в отношении молодежки в трех аспектах: политологическом, нормативно-правовом и социологическом. При этом именно политологическое толкование способно преодолеть ограниченность и непоследовательность Аругих дискурсов гуманитарного знания. Причина этого - незавершенность нормативно-правовой базы молодежной политики государства в современной России и незавершенность ее институциональной структуры [8] .

Наиболее актуальной проблемой модернизации государственной стратегии поддержкки молодежи до недавнего времени явцялось отсутствие комплекса цемей, задач и критериев результативности работы государственных и муниципальных институтов в молодежной среде. Напомним, что после 2006 г. было прекрашено действие федеральных џелевых программ «Молодежь России». Его последствия негативно влияют на современное состояние нормативной и конџептуальной базы государственной молодежной политики [9] . Нормативный статус «Основ государственной молодежной политики Россий- 
ской Федерации до 2025 года» представмяется недостаточным дия обеспечения системности работы органов государственной и муниџипальной власти в отношении молодежки.

В исследовательском сообществе существует прочное единство мнений по поводУ отправной точки модернизаџии молодежной политики, в соответствии с которой признается необходимость принятия профильного Федерального закона «О молодежки» и аналогичных региональных законодательных актов [10]. Безусловно, охват общественных отношений в молодежной среде ныне действующими наџиональными нормативными актами, последние из которых принимацись в 1995-1999 гг., явмяется несоразмерным современному состоянию развития российской молодежи.

Отметим, что укрепление конџептуального фундамента управления молодежной сферой невозможно без правовой защиты интересов молодых граждан России. Аля решения данной задачи требуется провести ревизию и систематизацию существуюшего корпуса правовых актов, относимых к жизнедеятельности молодежной среды. Необходимо устранить противоречия межАу действующим законодательством и современным состоянием социально-помитического процесса, что предполагает своевременную разработку новых юридически обязывающих документов или внесение рациональных корректив в принятые нормативно-правовые акты [11].

К 2020 г. депутатским корпусом всех уровней во взаимодействии с экспертным сообществом проделана огромная работа по нормативному обеспечению молодежной политики государства в Российской Федераџии. Шесть внесенных законопроектов в сфере молодежной политики за прошедшие годы были откАонены профильными комитетами ГосуАарственной Аумы или получияи отрицательную оџенку Правительства РФ. Наибольший интерес дмя аналитического обзора вызывают законопроект Федерального закона «О молодежи и государственной молодежжной политике в Российской Федерации», подготовленный Паматой молодых депутатов [12], а также проект закона о молодежной политике в Российской Федерации, внесенный в нижнюю палату российского парламента в июле 2020 г. Он разрабатывался в течение 2019 г. рабочей группой ГосуАарственного Совета при содействии депутатского корпуса обеих палат российского парламента. В период 2019 - начала 2020 г. он прошел всестороннее обсуждение в профильных комитетах палат Федерального Собрания с участием экспертов и представителей молодежных движений. Знаменательным событием в укреплении нормативного фундамента стратегии подАержки молодежи с полным основанием можно считать поправку в Конституцию РФ, принятую в числе изменений, утвержденных всенародным голосованием 1 июля 2020 г.: в п. 9 ст. 72 внесено дополнение о том, что в совместном ведении федеральной и региональной вмастей в современной России, помимо иных задач соџиальной поддержки, находятся и общие вопросы молодежной политики.

Именно с конституционной реформой смедует связать и решение проблемы принятия Федерального закона о молодежи после одобрения соответствуюшего законопроекта профимьными комитетами обеих палат российского парламента. 
Важным нормативным и конџептуальным достижением следует признать предложение об учреждении ежегодного докмада Росмолодежи перед Правительством РФ. Определено, что подготовка указанного документа Аолжна сопровождаться составлением корпуса статистических, соџиологических и иных показателей различных категорий и групп молодежи, систематизированных результатов проведенного мониторинга и оџенки качества реализаџии программ и проектов в сфере государственной молодежной политики.

Аостаточно обоснованным в проекте Палаты молодых законодателей Совета Федерации представляется определение структуры институџиональноуправленческого механизма молодежной политики государства. К высшему уровню структуры должен быть отнесен, во-первых, федеральный орган исполнительной власти, осуществляющий выработку государственной молодежной политики и стратегию ее нормативно-правового регулирования. Его иниџиативы должен осуществлять орган исполнительной власти федерального значения, на который возложена обязанность реализация политики в отношении молодежи. Очевидно, что к первому из них следует отнести Правительство РФ, а ко второму - Российское агентство по делам молодежи. Следующие управленческие уровни, отраженные в рассматриваемых законопроектах, представмяют органы государственной власти субъектов Федерации и аналогичные структуры мунищипальных образований.

К полномочиям органов государственной власти субъектов РФ предполагается законодательно отнести разработку и реализаџии приоритетов и основных направлений политики в отношении молодежи на территории отдельного региона. Эти же структуры призваны принимать и обеспечивать исполнение нормативных правовых актов субъектов РФ в сфере подлержки развития молодежи. Обоснованным представляется по аналогии с общенаџиональным уровнем учреждение института доклада о состоянии молодежи, который ежегодно Аолжен предоставляться каждым субъектом РФ, а также обязанность по разработке, и реализации на практике программ, выполняемых за счет средств российских регионов.

Авторы законопроекта рабочей группы Государственного Совета России, действовавшей в 2019-2020 гг., также ставили своей целью выстраивание системы государственных институтов в сфере молодежной политики и детализацию их полномочий на всех этапах деятельности государственного и муниџипального управмения.

Закономерно к сфере ответственности федеральных органов отнесены вопросы стратегического и конџептуального обеспечения молодежной политики в масштабах всей страны. В свою очередь, региональные органы государственной власти обязаны будут заниматься подготовкой кадров Аля управления развитием молодежи и проводить аналитическую обработку статистических данных в данной сфере. Аействия по артикуляџии и защите прав и соџиальных запросов молодых граждан и проведение мероприятий по работе с ними отнесены к сфере ответственности муниџипального управмения. 
Значительным прорывом в деме модернизации политики государства в отношении молодежи призвано стать выдемение единого органа по делам молодежи в системе политического управления. На 2020 г., помимо Росмолодежи, задачи поддержки молодых граждан возмагались и на профильные департаменты Министерств просвещения и образования РФ. Именно на Агентство по декам молодежи предлагается возможить обязанность ежегодного докмада в Правительстве РФ о состоянии молодежной политики и ведение особого реестра молодежных объединений, получающих доступ к государственному субсидированию. Весьма позитивным моментом выглядит констатация формирования расширенного реестра молодежных общественных организаций, действующих в Российской Федерации как при государственной поддержке, так и на самостоятельной основе, а также при содействии государственной или муниципальной власти.

Полагаем, что в законодательстве должно содержаться конкретное указание главных федеральных органов по делам молодежи, то есть Правительства РФ и Росмолодежи, равно как наименование органов регионального государственного управления субъектов Федераџии и их подраздемений - департаментов, управлений и т.п., в чью компетенџию входит организаџия работы с молоАежной соџиальной средой.

ОАним из наиболее актуальных направлений совершенствования нормативно-правовой основы соџиальной политики явцяется государственная поАдержка со стороны государства молодежкных проектов и инищиатив. Ее формами, как правицо, становятся общенаџиональные государственные программы и программы субъектов РФ. В их рамках молодым гражданам домжна оказываться организационная, информационная, методическая и консультативная поддержка, включая выделение на конкурсной основе грантов на реализацию молодежных проектов.

Обоснованной представляется попытка российских парламентариев законодательно закрепить систему молодежного самоуправления, детализировав структуру образующих ее органов. К таковым в законопроектах последних мет относили палаты (советы) молодых депутатов, молодежные парламенты, а также их аналоги в российских регионах и мунищипальных образованиях.

Разработчики законопроектов предпринимают попытки уточнить перечень молодежных парламентских институтов. Среди них ведущее место сегодня занимают Палата молодых законодателей верхней палаты российского парламента и Молодежный парламент при Государственной Ауме. Структурно их должны дополнять палаты (советы) молодых законодателей при представительных органах региональной государственной власти, а также молодежные парламенты, палаты и ассамблеи такого же уровня, молодежжные парламенты и совещательные советы, созданные при муниџипальных представительских институтах.

Анализ законопроекта, поступившего в Государственную Ауму 22 июля 2020 г. из рабочей группы Государственного Совета, показывает, что декларируемое в нем понятие «молодежной политики» с полным основанием следует отнести к сфере соџиальной политики Российского государства. Таковой счи- 
тается сфера сотрудничества и взаимодействия между ключевыми соџиальными субъектами - государством, объединениями гражданского общества и молодыми гражданами. Аостоинством этого законопроекта признаем формирование единого понятийного и категориального аппарата. Теперь доступно и аргументированно закрепляются понятия «молодежь (молодые граждане)», «молодая семья», «молодежные общественные объединения», «молодые ученые». При этом к данной категории предмагается отнести аспирантов, соискателей и кандидатов наук в возрасте до 35 мет, тогда как Аля докторов наук возрастной критерий устанавливается в 45 мет.

Настоящим прорывом следует признать повышение возрастного критерия возраста молодого гражданина, который теперь исчисляется от 14 до 35 мет. Эксперты прогнозируют, что в результате численность молодежжной соџиальной агрегации в России увеличится на 12,7 млн человек и достигнет $41 \mathrm{M \Lambda н}$ гражАан, то есть трети всего населения Российской Федераџии.

Отметим, что тем самым расширяется круг индивидов, получающих возможность права на соџиальную защиту со стороны пубцичной власти. К функџиям соџиальной политики с полным основанием можно отнести и такие направления реализации стратегии подАержкки молодежи, как помощь молоАым семьям, инвалидам и молодых гражданам, оказавшимся в тяжелой жизненной ситуации. СюАа же относится помощь в решении проблем получения Аоступного жилья, оказание соџиальных услуг. Кцючевое значение планируется придать агрегаџии соџиально значимых иниџиатив и развитию молодежного преАпринимательства, содействию в реализаџии молодыми АюАьми права на труа.

Вопросам профессиональной реализаџии молодых граждан, в отличие от предыдущих законопроектов, в варианте законодательной иниџиативы рабочей группы Государственного Совета посвящен специальный раздем. Формированию условий Аля молодежных иниџиатив молодых мюдей в сфере преАпринимательства предполагается уделить внимание в последующих подзаконных актах.

Оџенивая состояние конџептуальной основы подАержки властью и обществом развития молодежи через призму государственной соџиальной политики, подчеркнем, что давно назревшее принятие федерального закона в данной сфере станет отправным моментом в модернизации всего комплекса отношений по минии «государство - гражданское обшество». Вполне оправданным выглядит стремление унифицировать управленческую структуру молодежной политики и рационально распределить объем полномочий межАу ее уровнями. В то же время представляется необходимым не допустить чрезмерный перенос полномочий по подАержке молодежи в сферу ответственности муниципальных властей, что способно усугубить затяжной кризис развития института местного самоуправления в Российской Федераџии. В качестве выбора этапов алгоритма модернизаџии доктринальной основы молодежной политики преАставляется необходимой реализаџия конкретных мер:

- разработка и принятие нормативного акта / закона о молодежной помитики дия каждого субъекта РФ, который будет содействовать формирова- 
нию единой системы понятий и дефиниций, разграничению компетенции представительных и исполнительно-распорядительных органов региональной власти в сфере государственной поддержки молодежи;

- обеспечение надзора и контроля за соблюдением требований законодательства о государственной молодежной политике федеральными, региональными и муниџипальными вмастями;

- разработка и законодательное закрепление общенациональных критериев оценки эффективности реализаџии стратегии по подАержке молодежи органами государственного и муниципального управления, а также проведение общественных экспертиз программ и проектов в данной области.

Состояние развития молодежной среды, на наш взгляА, требует адекватного требованиям времени пересмотра структуры и полномочий институтов преАставительской власти, действующих в молодежном секторе государственной соџиальной политики. Аля этого необходимо создание профильных комитетов по делам молодежи в организационной системе палат российского парламента. По аналогии могут быть сформированы комитеты или комиссии по делам молодежи в структуре законодательных собраний субъектов РФ. Результатом Аолжно стать достижение органического единства межАу институциональным и нормативно-правовым компонентами молодежной политики.

\section{Библиографический список}

1. Скоробов А.П. О некоторых новых подходах к молодежной политике в условиях реформ // Социально-политический журнал. 1998. № 3. С. 132-134.

2. Государственная молодежная политика: российская и мировая практика реализации в обществе инновационного потенциала новых поколений / под общ. ред. В.А. Лукова. М., 2013.

3. Щенина О.Г. Приоритеты государственной молодежной политики // Молодежь России: сборник рефератов статей из периодических изданий за 2011 г. М., 2012. С. 58-61.

4. Крикунова В.А. Молодежная политика в современной России: понятие, субъекты, факторы формирования // Известия РГПУ им. А.И. Герцена. 2009. № 101. С. 277-283.

5. Кибанов А.Я., Ловчева М.В., Лукьянова Т.В. Социальная политика государства в отношении молодежи: модели, классификация, актуальные проблемы // Управление персоналом и интеллектуальными ресурсами в России. 2013. Т. 2, № 6. С. 21-28.

6. Слуикий Е.Г. Молодежная политика на рубеже веков: Вопросы теории и практики. СПб., 2008.

7. Цыбаков Д.Л. Борьба идеологий в современном политическом процессе: информационно-психологический аспект // Среднерусский вестник общественных наук. 2009. № 2. C. $129-132$.

8. Чирун С.Н. Молодежная политика: теория и практика взаимодействия. Кемерово, 2008.

9. Чуев С.В., Поляков М.Б. Основные проблемы развития сферы государственной молодежной политики // PolitBook. 2017. № 3. С. 45-63.

10. Меркулов П.А. Законодательное регулирование государственной молодежной политики в России // Сервис в России и за рубежом. 2013. № 2(132). С. 61-64.

11. Сайганова E.B. Совершенствование государственной молодежной политики посредством оптимизации нормативно-правовой базы // Известия Саратовского университета. Новая серия. 2017. Т. 7, вып. 1. С. 29-31.

12. Структура проекта Федерального закона «О молодежи и государственной молодежной политике в Российской Федерации». URL: https://yandex.ru/search/?1r=10\&clid=2233626\&text 